\title{
El derecho de reintegro de los gastos de electrificación en los procesos de urbanización. Los efectos del RD 1955/2000, de 1 de diciembre
}

\author{
Vicente Ortells Rubert \\ Profesor de Derecho Administrativo. Universitat Jaume I \\ Joaquín Llidó Silvestre \\ Secretario de Admón. Local
}

Sumario: I. INTRODUCCIÓN. II. EL DERECHO DE REINTEGRO. II.1. Aproximación conceptual. II.2. Su configuración legal. Referencias a la legislación urbanística. II.3. Un temprano criterio jurisprudencial. II.4. Sobre la extensión y límites del derecho. II.5. Conclusión. III. LOS DERECHOS DE ACOMETIDA. III.1. Aproximación conceptual. III.2. Obligados al pago: consumidores, usuarios y solicitantes. III.3. La dudosa legalidad de las incursiones urbanísticas del RD 1955/2000. IV. EL RÉGIMEN ESPECÍFICO DE LA OBLIGACIÓN DE SUFRAGAR EL COSTE DE LA VARIACIÓN DEL TENDIDO DE LAS LÍNEAS ELÉCTRICAS. IV.1. La regulación actual y sus precedentes. IV.2. La corriente jurisprudencial y su «rectificación consciente». IV.3. La regulación en el RD 1955/2000.

\section{INTRODUCCIÓN}

Una regulación manifiestamente mejorable de la obligación de extender las redes eléctricas para atender nuevos servicios ha hecho que esté a cargo de sujetos distintos en la normativa urbanística y en la del ramo eléctrico.

En efecto, según la legislación eléctrica [ahora arts. 9.1.g, 41.1.c) y 45.1.a) de la Ley 54/1997, de 27 de noviembre, del Sector Eléctrico, LSE] es obligación de las compañías distribuidoras "proceder a la ampliación de las instalaciones de distribución cuando así sea necesario para atender nuevas demandas de suministro eléctrico» $\mathrm{y}$ "atender en condiciones de igualdad las demandas de nuevos suministros eléctricos». De otro lado, según la legislación estatal sobre derechos y obligaciones urbanísticas de la propiedad inmobiliaria, son los propietarios de terrenos que, por su clasificación sean susceptibles de transformación urbanística, los que tienen el deber de dotarlos del servicio, entre otros, de suministro eléctrico [ahora, arts. 14.1; 14.2.e) y 18.3) y 6) de la Ley estatal 6/1998, de 13 de abril, sobre Régimen del Suelo y Valoraciones, 
LRSV, en concordancia con las exigencias de la legislación urbanística autonómica y el planeamiento].

La lógica del sistema impone que la ejecución de las infraestructuras necesarias para la provisión del servicio de suministro eléctrico se efectúe por el obligado en el proceso urbanizador y, en el seno del mismo, junto con las demás infraestructuras necesarias para la transformación urbanística de los terrenos. De modo que la norma de cierre del sistema sea el derecho de reintegro que, frente a las compañías eléctricas, ostentan los propietarios de terrenos que han costeado las infraestructuras eléctricas y, una vez instaladas, las entregan a las compañías distribuidoras de energía eléctrica, únicas que pueden (y deben) prestar el servicio de suministro eléctrico (ahora, art. 44.1 de la LSE y los antes citados de la misma), para que mediante su explotación hagan su legítimo negocio.

Lo cierto, en cambio, es que esa lógica no siempre es bien entendida y el ejercicio del derecho de reintegro ha sido, desde hace algún tiempo, objeto de litigio entre particulares y compañías eléctricas, ocupando a la Administración y a los Tribunales en la resolución de éstos y a la doctrina ${ }^{1}$ en la contribución científica a dar luz sobre un régimen jurídico complejo.

Partiendo, en líneas generales, de las conclusiones de estas aportaciones doctrinales, la secuencia del proceso de instalación de nuevas infraestructuras eléctricas, en síntesis, sin introducir ahora matices innecesarios para el presente propósito, sería la siguiente:

1. Los propietarios de los terrenos costean y ejecutan (esta última operación sólo en su caso) las infraestructuras eléctricas, en cumplimiento de los deberes que a ellos impone, de forma general, la legislación estatal sobre derechos y obligaciones urbanísticas de la propiedad inmobiliaria y que concreta la legislación y el planeamiento urbanísticos, según antes se ha dicho.

2. Los propietarios tienen el derecho de reintegro de los costes soportados frente a las compañías distribuidoras, a las que entregan aquellas infraestructuras.

\footnotetext{
${ }^{1}$ Entre las más recientes aportaciones: «Los derechos de acometida en los servicios públicos de suministro de agua potable y energía eléctrica», de J. V. Belenguer Mula, en REALA, n. ${ }^{\circ} 273$, enero-abril de 1997. «El derecho de los propietarios al reintegro de los gastos de instalación de las redes de suministro de energía eléctrica», de B. Colom Pastor, REALA, n. ${ }^{\circ} 278$, septiembre-diciembre de 1998. «El derecho de reintegro de los gastos de urbanización contra las compañías suministradoras de energía eléctrica», de J. CATALÁn Sender, en $R D U y M A$, n. $^{\circ} 165$, de noviembre de 1998.
} 
3. Las compañías distribuidoras se resarcen, a costa de los usuarios, de los costes repercutidos por los propietarios, a través de los «derechos por acometidas y demás actuaciones necesarias para atender los requerimientos de suministro de los usuarios» (art. 16.8 de la LSE).

Entre los costes necesarios para convertir los terrenos en solares no suelen ser menores, desde un punto de vista económico, los específicos de desvío de las líneas existentes, que las compañías eléctricas invariablemente intentan repercutir siempre en quien los promueve, asunto éste sobre el que, en un marco jurídico prácticamente inalterado desde 1966, como se verá, se han empezado a producir decisiones jurisprudenciales que modifican una tendencia hasta ahora acorde con las pretensiones de las compañías.

La promulgación del RD 1955/2000, de 1 de diciembre, por el que se regulan las actividades de transporte, distribución, comercialización, suministro y procedimientos de autorización de instalaciones de energía eléctrica, dictado en desarrollo de la LSE, ha venido a suscitar de nuevo las cuestiones que a la doctrina han ocupado en relación con este asunto de la implantación de nuevas redes eléctricas, por lo que seguidamente se analizará el modo en que pueden haber quedado afectados todos los asuntos a que se ha hecho referencia.

\section{EL DERECHO DE REINTEGRO}

\section{II.1. Aproximación conceptual}

El derecho de reintegro es el que asiste al propietario de los terrenos que, en cumplimiento de sus deberes urbanísticos, soporta los costes de dotación de infraestructuras eléctricas, a resarcirse de los mismos a cargo de las compañías que prestan el servicio de suministro eléctrico que, por tanto, se colocan en la posición de obligadas frente al propietario titular de tal derecho, justamente porque aquéllas vienen obligados, por mandato de los artículos 9.1.g), 41.1.c) y 45.1.a) de la LSE, a ampliar sus redes para atender nuevas demandas de suministros, obligación que, en los procesos de dotación integral de servicios urbanísticos, cumplen, por cuenta de aquéllas, los propietarios de los terrenos.

El derecho de reintegro viene a hacer efectivo el principio de interdicción de enriquecimiento injusto de las compañías eléctricas que, de no mediar tal derecho, verían cumplida una de las obligaciones que tienen 
legalmente impuestas sin inversión alguna a su costa y, es más, con plena disposición para reportarles los beneficios derivados de la explotación de su negocio.

\section{II.2. Su configuración legal. Referencias a la legislación urbanística}

El derecho de reintegro de los gastos de electrificación que se efectúan en el seno de actuaciones de dotación de servicios urbanísticos, se reconoce, por ello, no en la normativa del sector eléctrico sino en la urbanística.

Ya lo estableció el ahora revivido artículo 122.1.a) del Texto Refundido de la Ley del Suelo de 1976, cuando dispuso que «En los costes de urbanización que deban ser sufragados por los propietarios afectados se comprenden los siguientes conceptos: a) las obras de vialidad, saneamiento, suministro de agua y energía eléctrica, alumbrado público, arbolado y jardinería que estén previstas en los Planes y proyectos y sean de interés para el sector o área de actuación, sin perjuicio del derecho a reintegrarse de los gastos de instalación de las redes de suministro de agua y energía eléctrica con cargo a las empresas que prestaren los servicios, salvo la parte en que deban contribuir los usuarios según la reglamentación de aquéllos». En términos similares el artículo 59.2 del antiguo Reglamento de Gestión Urbanística de 1978, que añadió una previsión procesal: «Los costes de instalación se acreditarán mediante certificación expedida por la Administración actuante.»

El Texto Refundido de la Ley del Suelo de 1992, en su artículo 155.1.a), también incluyó el mencionado derecho de forma idéntica a como lo hizo el texto de 1976. Pero tal precepto, de carácter supletorio, según la Disposición final única del Texto, quedó anulado por inconstitucional en virtud del apartado $2 .^{\circ}$ del fallo de la Sentencia del Tribunal Constitucional (STC) 61/97, de 20 de marzo de 1997.

Ahora la legislación urbanística autonómica es la que debe ocuparse de la constitución y regulación de este derecho ${ }^{2}$.

\footnotetext{
${ }^{2}$ Así sucede, por ejemplo, con la Ley valenciana Reguladora de la Actividad Urbanística (LRAU), cuyo artículo 67.2 dispone que «el Urbanizador y los propietarios tendrán derecho a reintegrarse de los costes que sufraguen para extensiones de las redes de suministros, con cargo a las compañias que presten el servicio, salvo la parte correspondiente a las acometidas propias de la Actuación. Todo ello se entiende sin perjuicio de las previsiones que específicamente establezca la reglamentación del correspondiente servicio». La pormenorización del contenido de ese derecho viene establecido en la Orden de la Conselleria de Industria, Comercio y Turismo de 17 de marzo de 1991, sobre extensión de redes eléctricas (DOGV 1.534, de 3 de mayo de 1991), que regula las obli-
} 
La cuestión de los efectos que en tales normas autonómicas, en los aspectos que aquí interesan (el derecho de reintegro y su extensión, así como la intervención de la Administración del ramo urbanístico para certificar el importe de las inversiones efectuadas por los propietarios de los terrenos), haya podido producir la reciente entrada en vigor del Real Decreto $1955 / 2000$ ya citado, se ha de analizar con la base que aporta la jurisprudencia del Tribunal Supremo dictada en relación con la Administración titular de la competencia para regular el derecho de reintegro. En efecto, cuando el Alto Tribunal ${ }^{3}$ se ha enfrentado con la cuestión de la competencia para regular el derecho de reintegro y los instrumentos para su efectividad, ha establecido (SSTS de 27 de noviembre de 1995, RA 8870 y de 24 de octubre de 2000, RA 8176), rechazando las tesis de las compañías eléctricas, que es la Administración autonómica quien tiene competencia para regular tales materias en virtud de lo que dispone el artículo 31.9 del Estatuto de Autonomía de la Comunidad Valenciana, en el caso enjuiciado, en lo referente a la ordenación del urbanismo y en el artículo 32.1.5 en lo tocante al desarrollo legislativo y ejecución del régimen energético en el marco de la legislación básica del Estado, máxime cuando el Estado ha traspasado a la Comunidad Autónoma, cuya Orden de 27 de marzo de 1991 se controvertía, las funciones y servicios en materia de industria y energía, entre las que se encuentra, dicen las Sentencias citadas, la resolución de las discrepancias, dudas o interpretaciones de las normas y principios contenidas en el Reglamento de Acometidas a la sazón vigente y ahora derogado por el RD 1955/2000 [Disposición derogatoria única.d)].

Establecida pues la procedencia histórica de la regulación del derecho de reintegro en el seno de la materia «urbanismo» y la competencia autonómica para regularla, es ilustrativo, además, que el expresado $\mathrm{RD}$, en su parte general, en la que se refiere a las obligaciones de extensión de las redes eléctricas, se dicte al amparo de los títulos competenciales que al Estado reconoce el artículo 149.1.13. ${ }^{\text {a }}$ (bases y coordinación de la planificación general de la actividad económica) y 149.1.25. ${ }^{a}$ (bases del régimen minero y energético) de la Constitución. El Estado, al dictar el RD no invoca - no puede hacerlo- competencias en materia de urbanismo,

gaciones de extensión de las redes eléctricas a cargo, según los casos, de las empresas suministradoras y de los propietarios y regula el contenido del derecho de éstos a su reintegro a cargo de las primeras (art. 6.4), a la vez que establece (art. 8) la intervención de la Administración autonómica para resolver las controversias que se susciten entre los particulares y las compañías suministradoras sobre la aplicación de dicha Orden.

${ }^{3}$ A propósito de los recursos interpuestos por dos compañías eléctricas contra la Orden autonómica que se ha citado en la nota anterior. 
que es el título habilitante que otorga a su titular, las Comunidades Autónomas (art. 148.1.3. ${ }^{\mathrm{a}} \mathrm{CE}$ ), la competencia para regular el derecho de reintegro. Tampoco el Estado ha considerado que ésta sea una cuestión que afecte a las condiciones básicas que garanticen la igualdad de todos los españoles en el ejercicio de los derechos y en el cumplimiento de los deberes constitucionales a que se refiere el artículo 149.1.1. ${ }^{\mathrm{a}} \mathrm{CE}$, pues silencia el asunto en la norma que con base en ese título competencial ha dictado (la LRSV) afectando a los derechos y deberes urbanísticos de la propiedad inmobiliaria ${ }^{4}$.

Por tanto, el RD estatal citado, más en concreto, su Disposición derogatoria única, último párrafo, que deroga «cualquier otra disposición de igual o menor rango en lo que se oponga al presente Real Decreto» no puede haber producido efectos derogatorios de la normativa autonómica reguladora del derecho de reintegro, dictada por las Comunidades Autónomas en ejercicio de competencias que el Tribunal Supremo ha considerado propias de éstas. Es más, la expresión contenida en el artículo 43.1 del RD («sin perjuicio de lo establecido por las Comunidades Autónomas en el ámbito de sus competencias») al principio del capítulo que aborda la regulación de las obligaciones de electrificación, viene a ser una confirmación de que el RD se abstiene de normar en aquello que sea competencia autonómica - el derecho de reintegro, tal como se ha argumentado, lo es- - Y el RD menos todavía puede haber afectado al derecho de reintegro contenido en las normas autonómicas sobre urbanismo con rango de ley formal, que no pueden verse afectadas por el reglamento estatal, por razones tanto de jerarquía como de titularidad de los respectivos ámbitos competenciales.

\footnotetext{
${ }^{4}$ En este orden de cosas, J. CAtalán Sender, en op. cit. (p. 76) entiende que «Ni los artículos $14 y$ sobre todo 18 de la Ley 6/1998, de 13 de abril, sobre Régimen del Suelo y Valoraciones, contemplan expresamente este derecho de reintegro, sin duda porque, tras la sentencia del Tribunal Constitucional 61/1997 citada y el varapalo que ha dado la misma el Texto Refundido de la Ley del Suelo de 1991, ha entendido el legislador que es una submateria menor, de competencia de las Comunidades Autónomas; aunque a nuestro juicio este derecho debiera regularse del mismo modo en todo el territorio español, en aras del principio de igualdad ex artículo 149.1.1. ${ }^{a}$ de nuestra Norma Fundamental». Aunque así fuera, no se debe olvidar que conforme a la citada Sentencia «el título del artículo 149.1.1. ${ }^{a}$ CE no habilita para establecer una regulación uniforme de la propiedad privada y su función social, ni esa pretendida uniformidad puede servir de pretexto para anular las competencias legislativas que las Comunidades Autónomas tienen sobre las materias en las que entre en juego la propiedad» (FJ 9.a). Se estima, no obstante, que el título estatal no debe ser entendido como una prohibición de divergencia autonómica, porque las condiciones básicas que garanticen la igualdad no pueden consistir en un régimen jurídico acabado y completo de los derechos y deberes constitucionalmente afectados. Las condiciones básicas han de ser las imprescindibles o necesarias para garantizar la igualdad en el ejercicio de los derechos, pero no pueden consistir en una igualdad formal absoluta.
} 
Y otro dato a tener en cuenta: Tampoco el RD que se comenta ha podido afectar a la validez y eficacia del artículo 122.1.a) del revivido Texto Refundido de la Ley del Suelo de 1976, lo que tiene particular interés para aquéllos ámbitos autonómicos sin Derecho urbanistico o sin que el que hayan promulgado se ocupe del derecho de reintegro, toda vez que, por efectos de la STC 61/1997 citada, el expresado Texto ha quedado petrificado al no poder el Estado «derogar el que era su propio Derecho, en este caso sobre urbanismo, pero que ya ha dejado de serlo o, más exactamente, que ya no se encuentra a su disposición, ya sea para alterarlo (aun con eficacia supletoria) o para derogarlo» (FJ 10.d).

\section{II.3. Un temprano criterio judicial}

En el sentido que se acaba de concluir se pronuncia la temprana Sentencia del Juzgado de lo Contencioso-Administrativo n. ${ }^{\circ} 1$ de Castellón, de 8 de marzo de 2001, que, a modo de obiter dicta y al resolver un recurso interpuesto por una compañía eléctrica contra un acto de la Administración autonómica que fijaba el importe del derecho de reintegro a favor de un Ayuntamiento que había procedido a la dotación de infraestructuras eléctricas a los terrenos de una Unidad de Ejecución, señala lo siguiente:

«... el coste debe sufragarlo la empresa distribuidora, tanto en lo referente a las redes de alta y baja tensión como a los centros de transformación que aquéllos alimentan, sin que puedan repercutirse por formar parte del patrimonio de las empresas y de las inversiones precisas para atender las demandas de consumo de energía eléctrica que constituye la base de su negocio... No se puede pues pretender que el promotor asuma el coste de las instalaciones con el pretexto de que éste las traslade al comprador último, porque el TS ya señaló que este coste no se puede repercutir a los usuarios, precisamente porque las instalaciones son en todo caso, propiedad de la compañía suministradora y al usuario sólo se le trasladan los costes de la cometida individual... El Decreto 1955/2000 que dice la actora que ha venido a aclarar esta cuestión, no sólo es que no estaba vigente a la fecha en que se dictó el acto ahora impugnado, sino que no viene a variar el sentido de la Jurisprudencia analizada ni las conclusiones a que ésta llega, porque el artículo 45 no hace sino reiterar lo que ya dicen las normas urbanísticas y reiterar que el usuario sólo ha de abonar en la parte que le corresponda, los derechos de extensión y acceso, pero en modo alguno limita, ni puede hacerlo, el derecho al reintegro por parte del promotor» ${ }^{5}$.

\footnotetext{
${ }^{5}$ En igual sentido la Sentencia del mismo Juzgado de 12 de abril de 2001.
} 


\section{II.4. Sobre la extensión y límites del derecho}

Sentada la anterior conclusión importa analizar cuál es la extensión de ese derecho de reintegro y, en este orden de cosas, es necesario reiterar que la fijación de la amplitud o extensión y límites del derecho de reintegro también es materia propia de la legislación urbanística que la ha abordado desde el Texto Refundido de 1976 citado, cuando establece el «... derecho a reintegrarse de los gastos de instalación de las redes de suministro de agua y energía eléctrica con cargo a las empresas que prestaren los servicios, salvo la parte en que deban contribuir los usuarios según la reglamentación de aquéllos» [art. 122.1.a)] ${ }^{6}$.

La doctrina ${ }^{7}$ ha venido a entender que el derecho de reintegro, en las actuaciones urbanizadoras, alcanza a la totalidad de los gastos soportados por los propietarios de los terrenos. Esta conclusión tiene apoyo en los

\footnotetext{
${ }^{6}$ Ahora la legislación urbanística autonómica también establece la amplitud o extensión del derecho de reintegro. Así, el precepto legal citado en la nota 2 excluye de tal derecho «la parte correspondiente a las acometidas propias de la Actuación».

${ }^{7}$ En este sentido, «... surge a continuación otra pregunta, la de si los propietarios tiene derecho al reintegro de la totalidad de los gastos de instalaciones de la red de energía eléctrica o sólo a una parte de los mismos, todo ello debido a la redacción poco clara del artículo 122.1.a) de la Ley del Suelo que, tras reconocer el derecho al reintegro, añade «salvo la parte que deban contribuir los usuarios según la reglamentación de aquéllos». Dada su confusa redacción, dos son las interpretaciones posibles: a) La interpretación sistemática de los dos grupos normativos. La más lógica consiste en que los propietarios afectados tiene derecho al reintegro de la totalidad de los gastos, todo ello sin perjuicio de que las empresas distribuidoras peciban de los usuarios la parte que corresponda según la reglamentación del servicio a través de las tarifas, de los derechos de acometida y de los derechos por las demás actuaciones necesarias para atender los requerimientos de suministro de los usuarios... b) La interpretación literal del artículo 122.1.a) de la Ley del Suelo da lugar a un resultado absurdo. La segunda interpretación consiste en entender que los propietarios afectados sólo tienen derecho al reintegro de una parte de los gastos de instalación de las redes, esto es, entender que el artículo 122.1.a) de la Ley del Suelo reconoce el derecho al reintegro de la diferencia que hay entre los gastos que efectivamente se han producido y la parte con que deban contribuir los usuarios según la reglamentación del servicio. Lo que significaría entender que el artículo 122.1.a) de la Ley del Suelo remite a la reglamentación del servicio correspondiente al objeto de determinatr la parte con que deben contribuir los usuarios y, de esta manera, poder efectuar la resta. Si asi fuere, se llegaría al absurdo de que el quantum del reintegro a los propietarios afectados (por cierto, de imposible cuantificación a priori) estaría en función de la parte que deban contribuir los abonados o usuarios finales del servicio con el contrasentido de que, cuanto más grande fuera la contribución de los usuarios, menor sería la cantidad a reintegrar a los propietarios afectados. Esta interpretación, hoy superada, era la preconizada por la antigua Sala 4. ${ }^{a}$ del Tribunal Supremo en las dos sentencias que hay sobre el tema, que son la de 16 de diciembre de 1987, R. Ar. 9658, y la de 4 de octubre de 1988, R. Ar. 7433. Esta interpretación no sólo conculca el principio establecido en los artículos 9.1.g) y 41.1.c) de la Ley del Sector Eléctrico, sino que, además, y como ya hemos señalado, resulta que nos lleva a un absurdo...», en «El derecho de los propietarios al reintegro de los gastos de instalación de las redes de suministro de energía eléctrica», de B. Colom Pastor, op. cit., pp. 46 y ss.
} 


\section{más recientes pronunciamientos del Tribunal Supremo, entre los que des- tacan los siguientes:}

— Sentencia de 27 de noviembre de 1995 (RA 8870), dice: «Es verdad que los preceptos que establecen el marco competencial de la Comunidad Autónoma Valenciana en materia de energía, se preocupan de restringir su ámbito de ejercicio en un doble sentido: el de no afectar a otras Provincias o Comunidades, y en el de ejercerla dentro de la normativa básica estatal. Pues bien, la Orden que se cuestiona se ha limitado a interpretar esta normativa... en el sentido en que lo ha venido haciendo esta Sala del Tribunal Supremo (Sentencias de 6, 20, 23 y 29 de mayo de 1991, entre otras). En efecto, en ellas se señala que el Reglamento de Verificaciones Eléctricas... impone a las entidades distribuidoras la obligación de efectuar las ampliaciones necesarias para atender las exigencias del mercado eléctrico en las zonas que estén servidas por dichas entidades (art. 87.1) y de establecer los centros de transformación en condiciones y con capacidad bastante para proporcionar a las redes de distribución en baja tensión un suministro regular (art. 89), preceptos que están poniendo de manifiesto que el mantenimiento de las lineas conductoras en condiciones idóneas para atender las demandas normales de suministro - o en su caso el refuerzo de las mismas con este fin-no puede repercutirse a los usuarios porque forma parte de las empresas y de las inversiones precisas para atender las solicitudes de consumo de energía, que constituyen la base de su particular negocio, no siendo olvidable que las instalaciones de la red de distribución son, en todo caso, propiedad de la Compañia suministradora (art. 23.1 RD 2499/1982)... comportando la obligación de mantener, extender y ampliar, al menos en suelo urbano (art. 88), la red de distribución de energía eléctrica, no sólo la realización de la extensión y ampliación, sino que se efectúe con cargo a la empresa suministradora, de tal modo que el particular sólo precise construir la acometida individual» (FJ tercero), reproducida en la más reciente de 24 de octubre de 2000 (RA 8176).

— La de 16 de diciembre de 1997 (RA 9688), que dice: «El Reglamento de acometidas distingue, así, inversiones de responsabilidad, que son las necesarias para llevar a cabo el suministro de energía; inversiones en instalaciones de extensión e inversión total, que es la suma de las inversiones de responsabilidad y de extensión. Estas inversiones son a cargo de la empresa suministradora, porque constituyen el cauce para obtener sus legítimos beneficios económi$\cos y$, además, son inversiones que pasan a ser su propio patrimonio. El importe de estas inversiones no puede ser repercutido, en ninguna medida, a los usuarios.»

— La de 4 de marzo de 1997 (RA 1968), que recoge la doctrina jurisprudencial habida hasta entonces y cita un buen número de sentencias en la misma línea, señala que «... debiendo entenderse, por tanto, que la red de distribución comprende las ejecutadas en cumplimiento del mandato contenido en el artículo 87.1 del Reglamento de Verificaciones —declarado vigente por la jurisprudencia citada-de llevar las líneas hasta el punto en que el empalme por los particulares sólo precise construir la acometida individual que una dicha red de distribución con la mínima distancia a la caja de protección del usuario o a los seccionadores de entrada en alta tensión. Entenderlo de otra forma equivaldría a hacer recaer sobre el particular solicitante de una acometida individual el coste de instalaciones que beneficien a la colectividad en su conjunto y que por imperativo del men- 
cionado precepto debe sufragar la empresa distribuidora. Esto es lo que afirma el artículo 59.2 del Reglamento de Gestión Urbanistica...».

Importa de esta última Sentencia tanto la conclusión que alcanza como la conexión que establece entre la obligación de las compañías eléctricas de extender sus redes y el derecho al reintegro con sede en el ámbito material del urbanismo.

\section{II.5. Conclusión}

El RD 1955/2000 no puede alterar las conclusiones de la doctrina y jurisprudencia citadas en lo atinente a la extensión del derecho de reintegro, en el sentido de que las compañías eléctricas deben soportar el coste total de las infraestructuras implantadas en un proceso urbanizador y reintegrar a los propietarios de los terrenos los gastos que para ello hayan efectuado en cumplimiento de sus obligaciones. No las puede alterar porque siendo, como se ha dicho, el derecho de reintegro propio del ordenamiento urbanístico no puede haber afectado tal $\mathrm{RD}$ al contenido del mismo, habida cuenta de los títulos competenciales que legitiman la promulgación de dicho reglamento (arts. 149.1.13. ${ }^{\mathrm{a}}$ y $25 .{ }^{\mathrm{a}} \mathrm{CE}$ ). Y tampoco las puede alterar, desde la perspectiva sustantiva, porque las obligaciones de extender las líneas eléctricas que se contenían en el artículo 87.1 del Reglamento de Verificaciones Eléctricas, bajo cuya vigencia se produjeron aquellas decisiones jurisprudenciales, son ahora las que se contienen en los artículos 9.1.g), 41.1.c) y 45.1.a) de la LSE; manteniéndose vigente, por lo demás, el principio de interdicción del enriquecimiento injusto en el que se debe inspirar la armonización de los confusos regímenes jurídicos urbanístico y energético sobre la obligación de llevar a cabo la instalación de redes de suministro de energía eléctrica.

\section{LOS DERECHOS DE ACOMETIDA}

\section{III.1. Aproximación conceptual}

Los derechos de acometida son un instrumento de retribución de las compañías de distribución de energía eléctrica, como sin duda resulta del artículo 16.8 de la LSE, titulado «retribución de las actividades y funciones del sistema» incardinado en el título III de la Ley que se rotula «régimen económico»; lo que viene a ser confirmado por el artículo 44.1 del R.D. 1955/2000, en el que se dispone que «Tendrán la consideración de 
derechos de acometida la contraprestación económica que debe ser abonada a la empresa distribuidora por la realización del conjunto de actuaciones necesarias para atender un nuevo suministro o para la ampliación de uno existente». Los derechos de acometida son la otra cara de la moneda del derecho de reintegro (art. 16.8 LSE).

Los derechos de acometida tienen carácter único para todo el territorio nacional (art. 16.8 de la LSE), pero esta previsión se habrá de entender que lo es sin menoscabo de las competencias de las Comunidades Autónomas a quienes el artículo 3.3, apartados a) y b), de la propia LSE atribuye «el desarrollo legislativo y reglamentario y la ejecución de la normativa básica del Estado en materia eléctrica» y «regular el régimen de derechos de acometidas y las actuaciones necesarias para atender los requerimientos de suministro a los usuarios».

Los derechos de acometida pueden incluir los siguientes conceptos:

a) derechos de extensión, que son la contraprestación económica a pagar a las empresas distribuidoras por las infraestructuras eléctricas necesarias entre la red de distribución existente y el primer elemento propiedad del solicitante; $y$

b) derechos de acceso, que son la contraprestación económica a pagar por la incorporación a la red de un nuevo contratante de suministro o de ampliación del ya existente.

\section{III.2. Obligados al pago: consumidores, usuarios y solicitantes}

El obligado al pago de los derechos de acometida es, en principio, el usuario (art. 16.8 de la LSE) que en la terminología del Derecho vigente cuando se promulga tal Ley es la persona que «formaliza la póliza de abono para el suministro de la energía, en la que contrata una determinada potencia» (art. 1 del RD 2949/1982, de 15 de octubre, por el que se dan normas sobre acometidas eléctricas y se aprueba el Reglamento correspondiente, cuya vigencia se ha mantenido, bajo el imperio de la LSE, en cuya propia terminología el usuario puede ser identificado con el consumidor (arts. 9.2, 17.1 y 19 LSE, entre otros).

El RD 1955/2000 no sólo ha derogado el Reglamento de Acometidas de 1982, sino que ha alterado la letra de la LSE cuando atribuye la condición de «sujeto pasivo» de los derechos de acometida no a los usuarios, como hizo la LSE, sino a los solicitantes de un nuevo sumunistro. En efecto, el artículo 44.1.a) del RD dispone que los derechos de extensión 
que, recordemos, es uno de los conceptos que integran los derechos de acometida, corresponde satisfacerlos al «solicitante de un nuevo suministro o de la ampliación de potencia de uno ya existente», entendiendo por tal a «la persona física o jurídica que solicita las instalaciones de extensión para la acometida sin que necesariamente tenga que contratar el nuevo suministro o su ampliación» [art. 44.1.a)].

Podría parecer que el RD quisiera, al reconocerse inhabilitado para abordar la modificación del derecho de reintegro, recuperar de los solicitantes de nuevos suministros o de la ampliación de los existentes, es decir, de los propietarios obligados urbanísticamente a dotar de infraestructuras eléctricas a los terrenos, los importes que las compañías eléctricas se vean obligadas a reintegrarles por aquel concepto, pues no se puede entender de otro modo que en la LSE sea el usuario quien aparece nombrado como obligado en relación con el pago de los derechos de acometida y, en cambio, en el RD se impute esa obligación de pago a los solicitantes de nuevos suministros, cuando no es que haya desaparecido el usuario del conglomerado subjetivo de los efectos del RD pues, sin ir más lejos, en el artículo 43.2 se le cita como eventual obligado (distinto, por tanto, del solicitante de nuevos suministros) a que sus instalaciones receptoras de energía eléctrica estén en condiciones adecuadas. Por tanto, el usuario es un sujeto y el solicitante de nuevo suministro es otro y el RD ha querido que sea este último el obligado al pago de la parte de los derechos de acometida que se denominan derechos de extensión ("Derechos de extensión, siendo éstos la contraprestación a pagar por cada solicitante de un nuevo suministro...») No desmiente esta hipotética interpretación el artículo 45.3, tercer párrafo, del RD cuando establece que «... las empresas distribuidoras podrán participar en el coste de las infraestructuras eléctricas a que se refieren los párrafos anteriores», sino que viene a confirmar que ésta es la excepción a la regla general de que el costeamiento de las infraestructuras sea soportado en último lugar por los propetarios.

Si así fuera - sin perjucio de los excesos que en este punto pueda haber cometido en relación con el texto legal—, esa eventual interpretación del RD se habría de enfrentar con el principio que prohíbe el enriquecimiento injusto. Nótese, en relación con este asunto, que en la citada Sentencia del Juzgado de lo Contencioso-Administrativo de Castellón, después de hacer referencia a los eventuales cambios introducidos por el RD $1955 / 2000$, se sigue refiriendo al usuario como aquel que «ha de abonar en la parte que le corresponda, los derechos de extensión y acceso...», aunque esta declaración se ha de tomar con las reservas propias de no ser objeto del litigio la aplicación del comentado RD. 


\section{III.3. La dudosa legalidad de las incursiones urbanísticas del RD 1955/2000}

Sin perjuicio de los anteriormente apuntados excesos del RD 1955/2000 en relación con la LSE que desarrolla, también se debe reparar en que efectúa algunas incursiones en el campo material del urbanismo de dudosa procedencia desde el punto de vista del reparto constitucional de competencias, que conviene dejar referidas porque podría resultar que estuviese viciado el entero régimen de determinación de los derechos de extensión (art. 45 del RD) que retribuyen a las compañías eléctricas y gravan a los solicitantes de nuevos suministros.

En efecto, cuando aborda, en el Capítulo II ( Acometidas eléctricas y demás actuaciones necesarias para atender el suministro») del Título III ( (Distribución»), la regulación de los criterios para la determinación de los derechos de extensión que corresponde percibir a las compañías eléctricas distribuidoras en contraprestación por las infraestructuras eléctricas que deben ejecutar para atender un nuevo suministro o la ampliación de potencia de uno ya existente (arts. 44 y 45), las organiza sobre la base de la clasificación del suelo, de modo que se articula un distinto régimen de obligaciones a cargo de las empresas y los propietarios según lo sean de suelo urbano - distinguiendo entre el que tenga la condición de solar y el que no disponga de la misma (apartados 1 y 2 del art. 45) - , de suelo urbanizable (art. 45.3) o de suelo no urbanizable (art. 45.5). Así, de dicho régimen interesa (además de dejar constancia de que no se ajusta a la ley, al referirse al suelo urbano, a la distinción entre el consolidado por la urbanización o y el no consolidado por la misma, a pesar de que cita la LRSV) destacar ahora los siguientes aspectos:

1) El RD parece que altera el régimen de obligaciones del propietario del suelo urbano consolidado por la urbanización, toda vez que, cuando en el artículo 45.1 se refiere al suelo urbano que tenga la condición de solar establece como obligación de las empresas distribuidoras la de atender un nuevo suministro o ampliar uno ya existente realizando para ello las infraestructuras eléctricas necesarias dentro de ciertos límites, se contrapone a lo dispuesto en el artículo 14.1 de la LRSV que fija como deber del propietario (y sólo de éste) del suelo urbano consolidado por la urbanización el de completar a su costa la necesaria para que los terrenos alcancen la condición de solar que, por razón de la legislación y el planeamiento urbanístico, puede ser justamente la obligación de dotar de determinada infraestructura eléctrica. Se hace manifiesta aquí, una vez más, la dualidad de regímenes obligatorios que hacen recaer la carga de dotar de 
infraestructuras eléctricas en sujetos distintos, pero llama la atención que el propietario obligado por la LRSV puede verse privado del derecho a urbanizar y convertir en solar sus terrenos (art. 13 de la Ley citada), si, en base a las previsiones del RD, es la compañía eléctrica quien ha de cumplir la obligación de electrificación que le impone tal norma.

2) Al propietario del suelo urbano que no disponga de la condición de solar el RD le impone como obligación la de «completar a su costa... la infraestructura eléctrica necesaria para que se adquiera tal condición» (la de solar).

El texto reglamentario ha venido, por tanto, a configurar un concepto urbanístico (el de solar) al establecer que sólo cuanto éste tenga completa una determinada infraestructura (la eléctrica) alcanzará aquella condición. Ni siquiera el Texto Refundido de la Ley del Suelo de 1976 se atrevió a tanto, pues en éste, al definir el concepto de solar (art. 82.1. ${ }^{\circ}$ ) se remitió a las normas que, en su caso, estableciese el planeamiento correspondiente, igual como hizo el Texto Refundido de la Ley del Suelo de 1992 en su artículo 14 que resultó declarado inconstitucional por la Sentencia del TC 61/1997, de 20 de marzo, precisamente por el carácter supletorio de dicho precepto (apartado 2. ${ }^{\circ}$ del fallo de tal Sentencia), lo que evidenciaba la posición del legislador delegado estatal que, en 1992, entendió supletorio lo que ahora el Gobierno estatal, a través del RD 1955/2000 ha venido a calificar como básico, pues tal condición se otorga a todo el RD en virtud de su Disposición final primera 1.

Parece fuera de toda duda que el Gobierno ha adoptado una medida de carácter urbanístico (la configuración del concepto de solar) en una norma dictada al amparo de títulos competenciales que no habilitan para incidir en esa materia, ni siquiera indirectamente como ha hecho la LRSV, y con clara invasión de las competencias urbanísticas autonómicas y municipales que, indefectiblemente, han de entender restringida su capacidad para determinar bajo qué circunstancias de dotación de servicios unos terrenos determinados adquieren la condición de solar, no tanto porque el RD que se comenta exija que entre aquéllos esté el servicio eléctrico, sino porque el RD exige que éste se provea de un modo concreto y determinado, esto es, de acuerdo «... con las condiciones técnicas y de seguridad reglamentarias, como con las establecidas por la empresa distribuidora y aprobadas por la Administración competente...» que no es la urbanística (autonómica o local) sino la del ramo de la energía.

En relación con todo lo dicho, resulta significativo que la STC antes citada dijese, en relación con el artículo 20 del Texto Refundido de la Ley 
del Suelo de 1992, expresivo de los deberes legales de los propietarios de suelo, que «... la competencia del Estado para establecer unos deberes básicos no puede llegar a fijar el régimen jurídico de las dotaciones públicas, de los solares o de las licencias de edificación» (FJ 17.b in fine), respecto de lo cual la doctrina ${ }^{8}$ ha señalado que «si, por el contrario, los contemplados (sic) como términos púramente instrumentales...no pueden llegar a fijar el régimen jurídico de las dotaciones públicas, de los solares o de las licencias de edificación, no se ven afectadas de insconstitucionalidad», añadiendo que «el término solares parece como denominación de los terrenos de suelo urbano con urbanización completa (art. 13), cuyas condiciones no se precisan, lo que queda para la legislación urbanística. Tal condición es la base del derecho a edificar [arts. 13, 14.2.f) y 18.7]. Su utilización por el legislador estatal es instrumental, mientras que su contenido material corresponde al autonómico» Siendo evidente, por tanto, que tal inconstitucionalidad se produce cuando, como en este caso sucede, al llenar de contenido el concepto de solar por referir su régimen jurídico, en lo que ahora interesa, a la provisión del servicio de suministro de energía eléctrica en unas concretas y determinadas condiciones que el RD habilita a establecer, se están limitando negativamente las competencias de ordenación de las Comunidades Autónomas en materias que le son propias.

En este orden de cosas, también la doctrina ha afirmado que «... la ley (la LRSV) no dice qué debe entenderse por suelo urbano consolidado ni qué alcance jurídico tiene la denominación de solar, de modo que tales definiciones competen a la legislación de las CC.AA.» ${ }^{9}$.

3) Al propietario del suelo urbanizable, finalmente, se le impone como obligación la de «ejecutar a su costa, de acuerdo con las condiciones técnicas y de seguridad reglamentarias, como con las establecidas por la empresa distribuidora y aprobadas por la Administración competente, la infraestructura eléctrica necesaria, incluyendo la red exterior de alimentación y los refuerzos necesarios...», en relación con la cual vale lo dicho en el número anterior y añadir que de nuevo aquí se restringen las competencias de las Administraciones urbanísticas para determinar las condiciones para el desarrollo de los ámbitos del suelo urbanizable que les reconoce el artículo 16 de la LRSV según el cual al planea-

\footnotetext{
8 Juan Cruz Alli Aranguren, «De la Sentencia del Tribunal Constitucional de 20 de marzo de 1977 a la Ley 6/1998, de 13 de abril, de Régimen del Suelo y Valoraciones» publicado en Documentación Administrativa, n. ${ }^{\circ \mathrm{S}} 252-253$, p. 441.

9 José M. a BAÑo León, en «La nueva Ley del Suelo y la Sentencia del Tribunal Constitucional de 20-3-1997», en Documentación Administrativa, n. ${ }^{\text {ss }}$ 252-253, p. 161.
} 
miento general corresponde establecer las condiciones para el desarrollo de los ámbitos de suelo urbanizable.

Y no menos grave es la incursión que, en el campo del urbanismo, efectúa el artículo 47.5 in fine del RD, en el que se dispone que «en el supuesto de actuaciones urbanísticas, el suelo necesario para subestaciones y el suelo o locales destinados a centros de transformación, no computando a efectos de volumetría, se definirán como servicios dotacionales, en su caso infraestructuras básicas de suministro...». Con este precepto se predetermina la calificación que hayan de tener determinados inmuebles y se incide en técnicas e instrumentos urbanísticos que afectan a la actividad de la urbanización y edificación, propias del contenido material del urbanismo sobre el que el Estado no puede normar. En relación con esta cuestión sigue siendo válida la doctrina invocada con anterioridad y además es pertinente añadir que, en relación con la previsión del RD de no cómputo a efectos de volumetría de las subestaciones y centros de transformación, el Estado carece de título competencial para «... la delimitación completa y acabada del aprovechamiento urbanístico...» [FJ 17.c)].

\section{EL RÉGIMEN ESPECÍFICO DE LA OBLIGACIÓN DE SUFRAGAR EL COSTE DE LA VARIACIÓN DEL TENDIDO DE LAS LÍNEAS ELÉCTRICAS}

\section{IV.1. La regulación actual y sus precedentes}

La cuestión de a quién corresponde el pago del coste del desvío de las líneas eléctricas existentes cuando se llevan a cabo actuaciones por parte de la Administración viene ahora regulada en el artículo 58.2 de la LSE, que dispone: «La variación del tendido de una línea como consecuencia de proyectos o planes aprobados por la Administración comportará el pago del coste de dicha variación.»

Los precedentes de esta norma están en el artículo 7.2 de la Ley de 18 de marzo de 1966, n. ${ }^{\circ}$ 10/1966, de expropiación forzosa y servidumbre de paso para instalaciones eléctricas, que tiene un contenido similar al transcrito de la LSE: «La variación del tendido de una línea como consecuencia de proyectos o planes aprobados por la Administración en sus diversas esferas comportará el pago de dicha variación y de los perjuicios ocasionados.» Como se puede ver, la diferencia entre la Ley de 1966 y la vigente estriba en el matiz que representa la alusión a las «diversas esferas» de la Administración y la adición en el texto de 1966 del concepto in- 
demnizatorio «perjuicios ocasionados». Por lo demás, es de notar que la LSE, al menos expresamente, no derogó la Ley de 1966 (Disposición derogatoria única), aunque habría que entenderla sustituida por la vigente en aplicación de la derogación tácita que afecta a «cualquier otra norma en cuanto se oponga a lo dispuesto en esta Ley», sobre todo en lo que atañe a la inclusión como indemnizable de los perjuicios ocasionados que, en todo caso, su resarcimiento seguirá las reglas generales de la responsabilidad patrimonial.

La Ley de 1966 fue desarrollada en este particular por el Decreto 2619/1966, de 20 de octubre, por el que se aprueba el Reglamento de expropiación forzosa y sanciones en materia de instalaciones eléctricas, cuyo artículo 29.1 tiene la misma redacción que el artículo 7.2 de la Ley que desarrolla y en cuyo apartado 4 introduce la explicación procesal del modo de efectuar el resarcimiento e identifica a su acreedor: «Una vez firme la resolución aprobatoria del proyecto o plan del que resulte necesaria la ejecución de la variante de la línea, y llevada a cabo ésta, la Administración interesada en el citado proyecto o plan abonará a la entidad titular de la línea el coste de la variante y los perjuicios ocasionados.» El Decreto de 1966, a diferencia de lo que ocurre con su ley matriz, sí que ha sido expresamente derogado por el RD 1955/2000, según establece su Disposición derogatoria única, apartado c).

\section{IV.2. La corriente jurisprudencial y su «rectificación consciente»}

La interpretación inicial que de la normativa del año 1966 vinieron haciendo los Tribunales se puede sintetizar en la expresada en la Sentencia del Tribunal Supremo de 2-3-90 (RA 2125), en la que, al aceptar los fundamentos de la sentencia de la Sala territorial apelada, se dice:

«El reforzamiento del tendido e instalaciones supone una "variación del tendido" a que se refiere el artículo 29 del Decreto 2619/1966, de 20 de octubre, y el artículo 7, párrafo 2 de la Ley 10/1966, de 18 de marzo, de expropiación forzosa y sanciones en materia de instalaciones eléctricas, de aplicación a la presente litis. La variación del tendido admite, sin apartarse del texto legal, cualquier modificación en las líneas eléctricas que sean consecuencia de proyectos aprobados por la Administración incluyendo por tanto la Ley no sólo la modificación o variación del trazado de la línea sino las demás obras que tiendan a mejorar las condiciones de seguridad del tendido eléctrico y que FECSA se ve obligada a realizar por consecuencia de una obra pública. El importe que la Administración debe abonar a FECSA se configura en la Ley y el Reglamento citados con carácter indemnizatorio. De ahi que la variación del tendido no constituya una obra provincial, sino una instalación privada cuyo coste debe ser indemnizado por la Administración, según se deduce del párrafo 4 del artículo 29 del Reglamento, 
cuando se refiere al coste de la variante y los perjuicios ocasionados. La fijación de dicho importe debe fijarse conforme al procedimiento que señala el indicado precepto, extremo este que no ha sido cumplimentado en la tramitación del expediente, y que está pendiente de ultimar, dado que la Diputación, al rechazar la procedencia del pago no ha llevado a efecto valoración del importe de las prestaciones ni aceptado el presupuesto formulado por FECSA.» El Tribunal Supremo, por su parte, en los fundamentos jurídicos de su sentencia, añade lo siguiente: «Acreditadas las obras en los puntos indicados en el apartado anterior, consecuentes al trazado de nuevas vías de comunicación por la Diputación de Barcelona, resulta patente el derecho a la indemnización de la recurrente de los costes que importan aquéllas, de conformidad con lo dispuesto en el artículo 7.2 de la Ley de 18.3.66 y 29 del Reglamento de 20-X-66, toda vez que en el concepto a que se contrae el deber de indemnizar por la variación de un tendido de energía eléctrica como consecuencia de proyectos o planes aprobados por la Administración en sus diversas esferas comprende interpretando racional y literalmente el precepto legal mentado, la de toda obra que implique nuevo trazado de las líneas de conducción de esa energía, así como las que modifiquen su estructura, materiales componentes de las mismas o nuevas instalaciones en tanto éstas sean consecuencia de obras de la Administración de naturaleza viaria u otras determinantes de la variación de las instalaciones eléctricas, en las que se hallan incluidas las líneas de conducción; compaginando el ius variandi de la Administración con la obligada indemnidad de los propietarios; doctrina acorde con la de este Tribunal, Sentencia de 31-XII-86 y las que en la misma se citan, que debe aplicarse también al supuesto contemplado en este proceso de obras de reforzamiento de las líneas eléctricas.

Por Sentencias de esta Sala de 8-X-86 y 2-II-87, citadas por la Administración demandada, se ha sentado la doctrina que en virtud de lo dispuesto en la Ley y Reglamento meritados la cláusula de precariedad establecida con anterioridad a la vigencia de esas disposiciones, y aun las que se consignaran en Ordenanzas o contratos posteriores, no pueden enervar la virtualidad de aquellas cuyo efecto no retroactivo debe conectarse únicamente con la fecha del acontecimiento que determina tal modificación y no con la fecha del primer establecimiento de la línea eléctrica, según claramente lo indica la propia exposición de motivos de la Ley de 18 de marzo de 1966 y su Reglamento de 20 de octubre del mismo año, que se refiere siempre a las líneas existentes y no tan sólo a las que se tiendan en el futuro; precariedad y consecuente indemnidad de la Administración que no sería aplicable al supuesto contemplado en este recurso toda vez que las obras de reforzamiento de las líneas de conducción de energía eléctrica no suponen ninguna variación en su trazado manteniéndose el concebido al obtener la concesión sino la modificación de la instalación obediente a la normativa vigente a la que se adaptan las obras de la Administración; en cuyo coste debe comprenderse el derivado de las que afectan al tendido eléctrico a ejecutar por un tercero, la Compañia propietaria del mismo, que no pueden tampoco cargarse a cuenta del Estado como ente legislador, pues las obras son de la Diputación y en ellas se integran todos los gastos que se originen por las que realiza directamente o por contrata, así como las que por la legislación aplicable devienen de forzosa ejecución; debiendo las obras acomodarse a la normativa vigente carece de fundamento estimar una responsabilidad compartida entre esta Administración que proyecta y ejecuta esas obras y el Estado que promulgó la Ley o la Administración que dictó Reglamento en desarrollo de aquélla; pues de entender aplicable 
la doctrina expuesta por primera vez en esta instancia por la Diputación de Barcelona los condicionamientos legales o reglamentarios que originen unos costes, sea cual fuere su naturaleza, la persona privada o pública dueña de la obra podría reclamar del Estado o Administración Autónoma o Local el importe de aquellas que se realizan sin intervención alguna de las mismas y a las que compete la potestad legislativa o reglamentaria, pero que no son dueños de la obra ni han proyectado u ordenado su realización.»

El criterio del que es expresión la sentencia que se acaba de transcribir en lo necesario, fue alterado por el Tribunal Supremo en la Sentencia de 12 de febrero de 1998 (RA 1207) en la que los hechos enjuiciados son los siguientes, tomados del primer fundamento de derecho de tal sentencia: el Ayuntamiento de Valencia vendió una parcela de su propiedad a una inmobiliaria que pagó a Hidroeléctrica Española, S.A. 837.527 pesetas por el desvío del tendido eléctrico subterráneo existente en la parcela comprada al Ayuntamiento. La inmobiliaria reclamó del Ayuntamiento el reintegro de tal importe porque pensaba que no debía soportarla ella, sino que debía ser a cargo del Ayuntamiento que, por resolución de su Alcaldía confirmada en reposición, rechazó tal petición. El asunto llegó a la Sala de lo Contencioso-Administrativo del Tribunal Superior de Justicia de la Comunidad Valenciana que dictó sentencia estimando el recurso con base en el argumento de que, si bien es cierto que la compañía eléctrica no era titular de ninguna concesión municipal de ocupación de subsuelo de vía pública para la instalación de una conducción subterránea, sino que poseía sólo una autorización municipal a precario, sin embargo, tenía una razón que le permitía no costear el cambio de conducción y esa razón era el artículo 7.2 de la Ley 10/1966 y el artículo 29.1 del Reglamento que la desarrolla; preceptos interpretados por el Tribunal de instancia en el sentido de ser aplicable no sólo a los casos de existencia de una servidumbre de paso de energía eléctrica, sino también a los supuestos de simple autorización a precario y ello aunque se trate de autorizaciones anteriores a la Ley 10/1966, siempre que sea posterior a ella el acontecimiento que origina la modificación de la conducción eléctrica. La Sala Territorial siguió, por tanto, la doctrina jurisprudencial del Tribunal Supremo.

Pero, en este caso, cuando resuelve sobre la apelación de la Sentencia de la Sala territorial el Alto Tribunal va a modificar su criterio, el establecido en la Sentencia antes transcrita de 2.3.90 y las que ésta cita (y no halladas, dice la propia Sentencia que se comenta de 12.2.98) y va a cambiar de parecer dando una explicación muy pertinente:

«En la medida en que esta conclusión sea contraria a la de nuestra Sentencia de 2 marzo 1990... debe entenderse lo que ahora decimos como una rectificación 
consciente de aquella doctrina, pues una cosa es que la Administración no pueda, ni siquiera en casos de precario, privar del uso libremente y por puro capricho, y otra muy distinta (como aqui) de privación o variación justificada por razón de interés público, tenga la Administración que pagar e indemnizar a quien no paga nada.»

Así las cosas, estimando el recurso de apelación y revocando la sentencia de instancia, el Tribunal Supremo sobre el fondo de la cuestión dice:

"Reconoce la sentencia impugnada que en el presente caso "Hidroeléctrica Española" no tiene a su favor una servidumbre de paso, sino que la ocupación del subsuelo la hizo y la conserva en virtud de una mera autorización a precario.... Y a pesar de ello el Tribunal de instancia reconoce un derecho de indemnización por el traslado de la línea eléctrica en virtud de lo establecido en el artículo 7.2 de la Ley 10/1966... Sin embargo, este precepto se refiere a los casos en que la ocupación se hace a título de servidumbre de paso, como con toda evidencia se deduce de la colocación sistemática del precepto en la Ley (donde se encuentra en medio de la regulación de tales gravámenes)... sólo pues en estos casos de existencia de servidumbre es aplicable lo dispuesto en el artículo 7.2. Parece por lo demás, que distinguir, a efectos de cargar el coste de la variación de la línea, entre aquellos casos en que su titular disfruta de una servidumbre de paso... y aquellos otros en que disfruta del suelo ajeno en precario sin pagar merced alguna, resulta plenamente lógico, pues no podría entenderse el que, en casos como el presente, la entidad Hidroeléctrica Española haya usado gratuitamente el subsuelo de una vía pública desde el año 1958... y que además sea el Ayuntamiento quien haya de pagar la variación de la línea impuesta por los planes urbanisticos...»

\section{IV.3. La regulación en el RD 1955/2000}

La doctrina establecida en esta última sentencia, a propósito, como se ha dicho, del Derecho de 1966, es plenamente aplicable ahora bajo el imperio de la LSE y el RD 1955/2000. En efecto, la razón de decidir de la tal sentencia se apoya en la ubicación sistemática del precepto regulador de la indemnización conectado con la servidumbre de paso que, si nos atenemos a la Ley de 1966, aplicada en el caso analizado, es una norma dedicada a regular las expropiaciones forzosas y las servidumbres de paso para el establecimiento de las líneas eléctricas y si consideramos ahora la LSE, su ya citado artículo 58, está situado en el Título IX rotulado de forma significativamente similar a como se llamó la Ley de 1966, «Expropiación y servidumbres». Y, en el rango reglamentario, en el Decreto de 1966 el mismo régimen indemnizatorio se enmarca en su capítulo IV, titulado «Expropiación forzosa de bienes y derechos, imposición de servidumbre, urgente ocupación» y, en concreto, en la sección 2. ${ }^{a}$ del mismo que se titula «Definición, alcance y limitaciones de la servidumbre de 
paso. Modificación y variación de la misma. Extinción.» Ahora, la regulación reglamentaria de este asunto está en el capítulo V del título VII del RD 1955/2000, en el que se incluye el artículo 154 titulado, como su precedente artículo 29 del Decreto de 1966, «Variación del tendido de la línea como consecuencia de proyectos o planes aprobados por la Administración». Hay, por tanto, absoluta coincidencia en la posición sistemática de la regulación de las costes del desvío de líneas eléctricas entre la normativa actual y la de 1966 en base a la cual se produjo la Sentencia del Tribunal Supremo, en los términos que se han visto, citada en último lugar. 
REAL-2001, núm. 286-287. ORTELLS RUBERT, VICENTE y LLIDÓ SILVESTRE, JOAQUÍN. EL ...

REAL-2001, núm. 286-287. ORTELLS RUBERT, VICENTE y LLIDÓ SILVESTRE, JOAQUÍN. EL ... 


\section{Crónica y Documentación}

REAL-2001, núm. 286-287. ORTELLS RUBERT, VICENTE y LLIDÓ SILVESTRE, JOAQUÍN. EL ... 
REAL-2001, núm. 286-287. ORTELLS RUBERT, VICENTE y LLIDÓ SILVESTRE, JOAQUÍN. EL ...

REAL-2001, núm. 286-287. ORTELLS RUBERT, VICENTE y LLIDÓ SILVESTRE, JOAQUÍN. EL ... 